\title{
Altered Synaptic Dynamics during Normal Brain Aging
}

\author{
Ricardo Mostany, ${ }^{1}$ James E. Anstey, ${ }^{1}$ Kerensa L. Crump, ${ }^{1}$ Bohumil Maco, ${ }^{3}$ Graham Knott, ${ }^{3}$ and Carlos Portera-Cailliau ${ }^{1,2}$ \\ Departments of ${ }^{1}$ Neurology and ${ }^{2}$ Neurobiology, David Geffen School of Medicine at University of California Los Angeles, Los Angeles, California 90095, and \\ ${ }^{3}$ Centre of Electron Microscopy and Life Science Faculty, École Polytechnique Fédérale de Lausanne, CH-1015 Lausanne, Switzerland
}

What is the neuroanatomical basis for the decline in brain function that occurs during normal aging? Previous postmortem studies have blamed it on a reduction in spine density, though results remain controversial and spine dynamics were not assessed. We used chronic in vivo two-photon imaging of dendritic spines and axonal boutons in somatosensory cortex for up to 1 year in thy 1 GFP mice to test the hypothesis that aging is associated with alterations in synaptic dynamics. We find that the density of spines and en passant boutons (EPBs) in pyramidal cells increases throughout adult life but is stable between mature (8-15 months) and old ( $>20$ months) mice. However, new spines and EPBs are two to three times more likely to be stabilized over $30 \mathrm{~d}$ in old mice, although the long-term retention (over months) of stable spines is lower in old animals. In old mice, spines are smaller on average but are still able to make synaptic connections regardless of their size, as assessed by serial section electron microscopy reconstructions of previously imaged dendrites. Thus, our data suggest that age-related deficits in sensory perception are not associated with synapse loss in somatosensory cortex (as might be expected) but with alterations in the size and stability of spines and boutons observed in this brain area. The changes we describe here likely result in weaker synapses that are less capable of short-term plasticity in aged individuals, and therefore to less efficient circuits.

\section{Introduction}

Normal brain aging is associated with a decline in cognitive performance even in the absence of neurodegeneration (Park and Reuter-Lorenz, 2009; Grady, 2012; Morrison and Baxter, 2012). In addition, aging is associated with deficits in sensory perception (Dinse et al., 2006; Kalisch et al., 2009). The neuroanatomical basis for this age-related functional impairment has not been definitively established (Yeoman et al., 2012), but it probably does not involve a loss of neurons in the cerebral cortex (Tigges et al., 1990; Freeman et al., 2008). Instead, it likely depends on the maintenance of synaptic contacts between axonal boutons and dendritic spines (Hof and Morrison, 2004).

Decreases in spine density have been reported with brain aging in rodents (Feldman and Dowd, 1975; Leuba, 1983; Wallace et al., 2007), nonhuman primates (Page et al., 2002; Dumitriu et al., 2010), and humans (Anderson and Rutledge, 1996). The magnitude of spine loss seems to correlate with the degree of functional impairment (Peters et al., 2008; Dumitriu et al., 2010). Paradoxically, other studies describe age-related increases in spine density (Connor et al., 1980) and in synaptophysin immunoreactivity (Benice et al., 2006). Large and small spines may be differentially vulnerable to aging, which is interesting considering

\footnotetext{
Received Oct. 11, 2012; revised Jan. 14, 2013; accepted Jan. 16, 2013.

Author contributions: R.M. and C.P.-C. designed research; R.M., B.M., G.K., and C.P.-C. performed research; R.M. contributed unpublished reagents/analytic tools; R.M., J.E.A., and K.L.C. analyzed data; R.M. and C.P.-C. wrote the paper.

This work was supported by a generous gift from the Parkinson Alliance (C.P.-C.) and by Swiss National Science Foundation Synergia Grant CRF II313470/1 (G.K.).

The authors declare no competing financial interests.

Correspondence should be addressed to Ricardo Mostany at his present address: Department of Pharmacology, Tulane University School of Medicine, 1430 Tulane Avenue SL-83, New Orleans, LA 70112. E-mail: rmostany@tulane.edu.

DOI:10.1523/JNEUROSCI.4825-12.2013

Copyright $\odot 2013$ the authors $\quad 0270-6474 / 13 / 334094-11 \$ 15.00 / 0$
}

that synaptic strength is related to spine volume (Kasai et al., 2010). For example, layer $2 / 3$ (L2/3) pyramids in aged animals preferentially lose small thin and stubby spines but not the larger mushroom spines (Dumitriu et al., 2010), although another study showed that the density of thin spines increases with age (Connor et al., 1980). These discrepancies might be a result of sampling bias inherent to Golgi-type studies (Holtmaat and Svoboda, 2009). For human data, the potential effects on spine density of concomitant health problems or delays until tissue fixation could have been magnified in older subjects. In addition, postmortem studies have the drawback that dynamic changes in dendritic spines cannot be assessed.

Recent studies in mice using in vivo two-photon microscopy have demonstrated that changes in spine dynamics (but not spine density) are critical for brain rewiring in the context of experiencedependent plasticity (Holtmaat and Svoboda, 2009), motor learning (Yu and Zuo, 2011), or stroke (Murphy and Corbett, 2009). Therefore, it is conceivable that the deficits in working memory and reasoning ability that characterize mild cognitive impairment in older individuals (Morrison and Baxter, 2012) could be associated with changes in synapse dynamics. Only one previous in vivo twophoton imaging study examined the effects of aging on spines in mice; it found that spine density was stable during normal aging but did not examine spine dynamics beyond $1 \mathrm{~h}$ of imaging (Spires-Jones et al., 2007). Other in vivo imaging studies of spines did not investigate age-related changes in their dynamics (Trachtenberg et al., 2002; Holtmaat et al., 2005; Zuo et al., 2005). Even less is known about the fate of axon boutons with aging, although their much lower turnover compared with spines in adult mice (De Paola et al., 2006) suggests they might not change. Here, we set out to test the hypothesis that normal aging is associated with changes in the size and stability of presynaptic and postsynaptic elements. 


\section{Materials and Methods}

Animals and materials. We used GFP-M transgenic mice (male and female) expressing GFP under the Thy-1 promoter (Feng et al., 2000) from four different age groups: $<1$ month (juvenile), 3-5 months (young adults), 8-15 months (mature adults), and $>20$ months (old adults). Animals were housed with food and water ad libitum. We ensured that all the animals had their whiskers intact during the entire imaging period. All the procedures described in this study were approved by the University of California Chancellor's Animal Research Committee. All materials were purchased from Sigma-Aldrich unless otherwise stated.

Window surgery. Chronic glass-covered cranial windows were implanted as described previously (Mostany and Portera-Cailliau, 2008; Holtmaat et al., 2009). Briefly, mice were anesthetized (isoflurane, $1.5 \%$ via nose cone) and placed on a stereotaxic frame. Dexamethasone $(0.2$ $\mathrm{mg} / \mathrm{kg}$; Baxter Healthcare Corp.) and carprofen ( $5 \mathrm{mg} / \mathrm{kg}$; Pfizer) were administered subcutaneously to reduce brain edema and local tissue inflammation. A 4-mm-diameter craniotomy was performed with a pneumatic dental drill over the primary somatosensory cortex, $3 \mathrm{~mm}$ lateral to the midline and $1.95 \mathrm{~mm}$ caudal to bregma. A $5 \mathrm{~mm}$ glass coverslip (\#1; Electron Microscopy Sciences) was gently laid over the dura mater and glued to the skull with cyanoacrylate-based glue. Dental acrylic was then applied throughout the skull surface and up to the edges of the coverslip. A titanium bar $(0.125 \times 0.375 \times 0.05$ inches $)$ was embedded in the dental acrylic to secure the mouse onto the stage of the microscope for imaging.

High resolution in vivo two-photon imaging of spines and en passant boutons. Imaging was done under light isoflurane anesthesia (1-1.5\%) with a custom-built two-photon microscope, using a Ti:sapphire laser (Chameleon Ultra II; Coherent) tuned to $910 \mathrm{~nm}$, a $40 \times 0.8$ NA waterimmersion objective (Olympus), and ScanImage software (Pologruto et al., 2003) written in MATLAB (The MathWorks). Mice were allowed to recover from the surgery for at least 3 weeks before the first imaging session, except for those in the juvenile group, which only recovered for $8-12 \mathrm{~d}$ before imaging. We have previously shown that GFP-M mice exhibit stable spine dynamics over several months starting $\sim 1$ week after cranial window surgery (Holtmaat et al., 2009).

High-magnification images $(512 \times 512$ pixels, $0.152 \mu \mathrm{m} /$ pixel, $1.5 \mu \mathrm{m}$ $z$ steps) were obtained for the analysis of dendritic spines in apical tufts of L5 pyramidal neurons. The identity of L5 pyramidal neurons was confirmed using low-magnification image stacks collected from the pial surface to the soma $(512 \times 512$ pixels, $0.72 \mu \mathrm{m} /$ pixel, $5 \mu \mathrm{m} z$ steps $)$. Axonal segments belonging to L2/3 and L5 pyramidal cells [type A3 axons (De Paola et al., 2006)] were also imaged at high resolution for the analysis of en passant boutons (EPBs). In GFP-M mice, the vast majority of neurons that express GFP are in L5; therefore, we assume that the majority of A3 axons that we imaged and analyzed belonged to L5 neurons. Imaged dendrites and axons were in $\mathrm{L} 1$ (within the first $100 \mu \mathrm{m}$ from pia mater). Regions of interest (ROI) containing long dendritic and axonal segments were selected at random for chronic imaging throughout the window. For each animal, dendritic spines and EPBs were imaged $4 \mathrm{~d}$ apart every month for as long as the optical clarity of the cranial window allowed (minimum of $8 \mathrm{~d}$, maximum of 13 months).

We and others previously addressed the question of whether chronic in vivo imaging influences spine density. We compared spine density of layer 5 pyramidal neurons in adult GFP-M mice that were imaged in vivo through a glass-covered cranial window versus GFP-M mice that were perfused and imaged in fixed tissue slices and found no significant differences $[0.28 \pm 0.06$ spines $/ \mu \mathrm{m}$ in naive perfused mice vs $0.30 \pm 0.07$ spines/ $\mu \mathrm{m}$ for imaged mice; $t$ test, $p=0.44$ (Holtmaat et al., 2009)].

Near infrared branding and serial section EM reconstructions. At the end of the in vivo imaging sessions, two mice were perfused with $2.5 \%$ glutaraldehyde and $2 \%$ paraformaldehyde in $100 \mathrm{~mm}$ phosphate buffer, $\mathrm{pH}$ 7.4. The fixed brains were sliced $(60 \mu \mathrm{m})$ parallel to the cranial window plane, and the first slice was imaged again with two-photon microscopy to locate the previously imaged dendrites and axons, using blood vessel imprints on the cortical surface as a guide. Next, the tissue was branded using line scans at higher laser power, as described previously (Bishop et al., 2011). These fiducial marks could later be used to locate the ROIs in the plastic embedded tissue. After laser branding, the tissue was washed in cacodylate buffer $(0.1 \mathrm{M}, \mathrm{pH} 7.4)$ and postfixed for $40 \mathrm{~min}$ with $1.5 \%$ potassium ferrocyanide and $1 \%$ osmium tetroxide, again for $40 \mathrm{~min}$ in $1 \%$ osmium tetroxide alone, each in $0.1 \mathrm{~m}$ cacodylate buffer, and finally for $40 \mathrm{~min}$ in $1 \%$ aqueous uranyl acetate. Sections were then dehydrated in a graded alcohol series and infiltrated with Durcupan resin overnight. Finally, the section was embedded flat between glass slides in fresh resin and polymerized for $24 \mathrm{~h}$ at $65^{\circ} \mathrm{C}$. The resin-embedded tissue was then glued to a flat $1-\mathrm{mm}$-thick slab of blank resin for trimming in the ultramicrotome. The final trimmed block containing the ROIs was then mounted onto an aluminum stub using conductive carbon paste and coated with a $30 \mathrm{~nm}$ layer of gold (Cressington vacuum evaporation system).

Tissue blocks were imaged inside a NVision 40 FIBSEM microscope (Carl Zeiss) as described previously (Knott et al., 2011). For the final serial imaging, we used an acceleration voltage of $2 \mathrm{kV}$ with a current of between 340 and $400 \mathrm{pA}$ and dwell time of $10 \mu \mathrm{s} /$ pixel. The images were collected at a magnification of $9 \mathrm{~nm} /$ pixel and with a total image size of $2495 \times 2495$ pixels, which corresponds to a field size of $22.45 \times 22.45$ $\mu \mathrm{m}$. The milling depth after each image was $17.79 \pm 1.59 \mathrm{~nm}$ as determined by the cylindrical diameters method (Fiala and Harris, 2001). For analysis, the individual images acquired by the FIBSEM microscope were combined into a single image stack file (made up of 1008 images) and aligned in the Fiji software package (http://fiji.sc/wiki/index.php/Fiji). The total volume used for the $3 \mathrm{D}$ reconstruction was $22.45 \times 22.45 \times$ $19.15 \mu \mathrm{m}$. The labeled dendrites and axons were manually segmented using the TrakEM2 program (Fiji software package), and the final visualization of the reconstructed 3D model was rendered in the Blender software (version 2.57; Blender Foundation, http://www.blender.org).

Analysis. Data on the density and dynamics of spines and boutons were obtained using spine analysis software written in MATLAB (kindly provided by T. O'Connor and K. Svoboda, Janelia Farm). All visible spines were scored, including those projecting along the $z$-axis, provided they protruded beyond the noise of the dendritic shaft. We analyzed dendritic spines from $n=8$ cells $(n=3$ mice $), n=19(n=7), n=48(n=11)$, and $n=24(n=8)$ from the juvenile, young, mature, and old groups, respectively. EPBs were detected as regions of high GFP brightness along the axon (fluorescence intensity $>2$ standard deviations higher than the axonal shaft). We analyzed EPBs from three, seven, nine, and eight mice in the juvenile, young, mature, and old groups, respectively. We used equivalent numbers of mice and cells at different age groups, and in no case was the majority of data coming from a single cell or animal at a given time point. This was especially important for the mature group since an unequal distribution of the data along its somewhat longer span (8 months) could easily have led to biased results.

In this study, we tracked a total of 11,936 distinct dendritic spines over 2-22 imaging sessions, for a total of 34,936 spines being scored at least once (including gained and lost spines) over $15.8 \mathrm{~mm}$ of total dendritic length. The average length of dendritic segments analyzed in each ROI was $55.1 \mu \mathrm{m}$, and each ROI had an average of 20.7 spines at the first imaging session. In terms of type A3 axonal boutons, we tracked a total of 2764 distinct EPBs over two to four imaging sessions, for a total of 6041 boutons over $14.9 \mathrm{~mm}$ of total axonal length. Results were averaged over the imaging period, unless the imaging spanned over two age groups, in which case only data from the months belonging to each age group were averaged separately.

Dynamics of spines (or boutons) are expressed as a function of dendritic (or axonal) length. We did not calculate fractions of gained or lost spines/boutons because changes in the density of spines/boutons at different ages would have influenced these numbers significantly. The survival function of spines present the first day of imaging was obtained by fitting the survival fraction plots to a single exponential decay curve. Survival fraction and half-life were calculated as follows: survival fraction $=$ stable fraction + unstable fraction $\times \mathrm{e}^{-\mathrm{t} / \tau}$, where $t$ is the time (days) and $\tau$ (tau) is the time constant; half-life $=\tau \times \ln (2)$.

Volumetric estimations of dendritic spines and EPBs and the sorting of dendritic spine subtypes were done using custom-written routines in MATLAB and ImageJ (http://rsb.info.nih.gov/ij/). Dendritic spine volume was calculated as the total integrated brightness (TIB) of each protrusion divided by the TIB of a perpendicular straight line drawn over the dendritic shaft adjacent to the spine. 
Semiautomated sorting of the subtype of dendritic spines (stubby, thin, and mushroom) was performed first based on the presence or not of a head and then based on the length of the protrusion. To determine the presence or absence of a bulbous spine head, we obtained pixel intensity values from manually drawn lines along the axis of each protrusion, and the first derivative function $(D f)$ of each trace was obtained. A headless protrusion was scored if the $D f_{\mathrm{x}}$ did not cross $y=0$, and a spine head was scored if the $D f_{\mathrm{x}}$ crossed $y=0$ twice (a neck was considered as the first time that $D f_{\mathrm{x}}=0$, and the center of the head was considered as the second time $D f_{\mathrm{x}}=0$ ). Protrusions with a head were classified as mushroom, regardless of length. Of the protrusions that did not have a head, those shorter than $0.7 \mu \mathrm{m}$ were considered stubby spines (spine length similar to neck diameter but less than dendrite diameter), whereas those measuring $\geq 0.7 \mu \mathrm{m}$ in length were considered thin spines (a small subset of spines had lengths $>3 \mu \mathrm{m}$, and among them a few appeared to have small swellings at the tip, but these were not detected as being a spine head by the algorithm described above).

EPBs were scored using a semiautomated routine custom written in ImageJ and MATLAB. EPBs were detected based on fluorescence intensity plots, calculated as the average linear intensity of a 5-pixel line $(0.15$ $\mu \mathrm{m}$ per pixel) drawn along the axonal shaft in individual slices of the image stack. The volume of EPBs was calculated as the TIB of the scored bouton divided by the average integrated brightness of the shaft. For display purposes only, best projections of the dendritic and axonal segments were obtained (the best focal plane is identified and overlaid in Adobe Photoshop; Adobe Systems), preserving all the elements in the segment, and a median filter (radius of 1) was applied.

Statistics. Statistical differences between groups were calculated with one-way ANOVA followed by a Bonferroni's multiple comparison test. The extra sum-of-squares $F$ test was used to compare the best-fit values for the survival function parameters. A Student's $t$ test was used to compare single parameters between two groups. All statistical analyses were performed with GraphPad Prism (GraphPad Software). All data are presented as the mean \pm SEM. Significance was set at $p<0.05$. In the figures, ${ }^{*} p<0.05,{ }^{* *} p<0.01$, and ${ }^{* *} p<0.001$.

\section{Results}

\section{The density and $4 \mathrm{~d}$ turnover of spines in somatosensory cortex increases throughout adulthood, and their volume is smaller in old mice}

We used high-resolution chronic in vivo two-photon imaging through a cranial window in GFP-M transgenic mice (Feng et al., 2000) to monitor the density, size, and dynamics of individual dendritic spines of L5 pyramidal neurons in neocortex. Imaging was done at four different ages that encompass the entire lifespan of the mouse (Russell, 1966): juvenile ( $<1$ month), young adult (3-5 months), mature ( $8-15$ months), and old ( $>20$ months). These ages were chosen because they matched those of previous studies (Connor et al., 1980; Adams and Jones 1982; Leuba, 1983; Bloss et al., 2011). Visual inspection of dendrites revealed striking and unexpected changes in the density and size of spines throughout the life of the mouse (Fig. 1a). Many spines in juvenile mice were long and thin, whereas those in old mice tended to be short and small. Large mushroom-type spines were most apparent in the mature group. Spines appeared to be least densely packed in the young adult mice and more densely packed in the old mice.

To quantify these observations, we analyzed spines within stacks and calculated the density, turnover, volume, and lifetime of spines. There was a dramatic $(>50 \%)$ decrease in spine density between the juvenile and young adult groups $(0.54 \pm 0.02$ vs $0.26 \pm 0.02$ spines/ $\mu \mathrm{m} ; p<0.001$, unpaired $t$ test; Fig. $1 b$ ), which is consistent with the previously described phenomenon of pruning of spines after the third postnatal week (Holtmaat et al., 2005; Zuo et al., 2005). Similarly, spine turnover ratios were reduced more than threefold between juvenile and young adult stages $(0.38 \pm 0.03$ to $0.11 \pm 0.01$ for the juvenile and young groups, respectively; $p<0.001$, unpaired $t$ test; Fig. 1c). Because of the considerable differences in spine density and turnover between juvenile and young adult mice, we subsequently considered the three groups of adult mice separately from juvenile mice in the analysis.

Throughout the adult life of mice (young, mature, and old age groups), the density and dynamics of dendritic spines also changed significantly and in unanticipated ways. Rather than the expected spine loss with aging, we observed that the density of spines increased by as much as $65 \%$ (from $0.26 \pm 0.02$ spines $/ \mu \mathrm{m}$ in the young adult group to $0.40 \pm 0.01$ and $0.43 \pm 0.02$ spines/ $\mu \mathrm{m}$ in the mature and old groups, respectively; $p<0.001$, Bonferroni's post hoc test; Fig. 1b). Furthermore, although we anticipated that spines would be less dynamic in older mice (to explain the impaired working memory), we found that dendritic spine turnover increased significantly throughout adult life (from $0.11 \pm 0.01$ in the young adult group to $0.15 \pm 0.01$ and $0.16 \pm 0.01$ in the mature and old groups, respectively; $p<0.01$, Bonferroni's post hoc test; Fig. 1c).

Previous in vivo imaging studies have reported that larger spines (e.g., mushroom spines) are more stable, whereas smaller spines (e.g., thin or stubby spines) are more dynamic (Holtmaat and Svoboda, 2009). We used a semiautomated and unbiased classification scheme (see Materials and Methods) to distinguish three different types of spines (mushroom, thin, and stubby) depending on their morphology. Not surprisingly, we found a higher proportion of thin spines in juvenile mice, but there were no differences in the relative proportions of spine subtypes within the adult groups (Fig. 1a,d). We also calculated spine volume and found a significant decrease in spine volume between the mature and the old groups $(7.82 \pm 0.33$ vs $6.38 \pm 0.35$ A.U.; $p<0.01$, Dunn's post hoc test; Fig. 1a,e).

Thus, we conclude that neurons in this specific area of the cortex experience previously unforeseen changes in spine density, dynamics, and volume throughout the adult mouse lifespan. Importantly, even though there were no differences in spine density or turnover after 8 months of age (midadult stage), spines were smaller in old mice compared with mature mice, highlighting the fact that old mice exhibit unique changes in dendritic spines.

\section{Longitudinal imaging in adult mice over 4-12 months shows that spine density is stable in old mice}

An important advantage of our in vivo imaging approach with cranial windows is that individual neurons can be imaged repeatedly, in many cases over several months, which eliminates potential sampling biases of previous postmortem studies that had to pool together data from different mice at different ages. Therefore, we tracked individual cells of mature mice for several months ( $n=10$ cells from four mice; Fig. $2 a$ ) and found that, on average, dendritic spine density in this group increases significantly over a 4 month period $(0.34 \pm 0.03$ vs $0.37 \pm 0.02$ spines/ $\mu \mathrm{m}$ for days 1 and 120 of imaging, respectively; $p<0.05$, paired $t$ test; Fig. $2 b$ ). Using the same chronic imaging approach over 4 months in the old group ( $n=9$ cells from three animals), we detected no significant differences in spine density (Fig. $2 c, d$ ), suggesting that the changes that lead to higher numbers of spines in the old mice occur earlier, in the mature stage and/or in the transition from the mature to the old stage. Indeed, when we imaged L5 neurons in a single animal for $>12$ months, encompassing the mature and old stages of adult life (Fig. 2e), we again observed a significant increase in spine density $(0.40 \pm 0.02 \mathrm{vs}$ $0.49 \pm 0.03$ spines $/ \mu \mathrm{m}$ at 1 and $360 \mathrm{~d}$ of imaging, respectively; $n=7$ cells; $p<0.05$, paired $t$ test; Fig. $2 f, g$ ). These results imply that the gradual increase in spine number throughout adulthood 
a
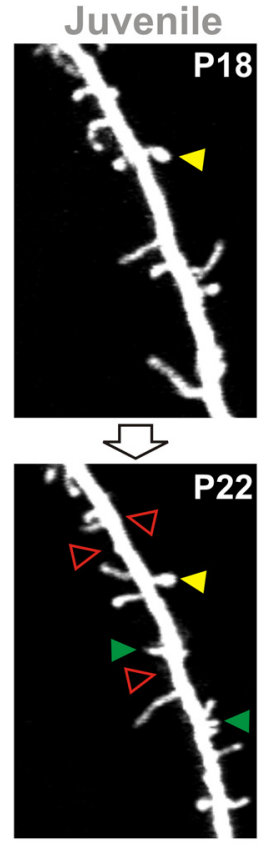

b

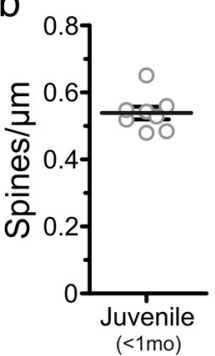

d

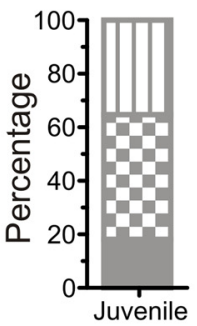

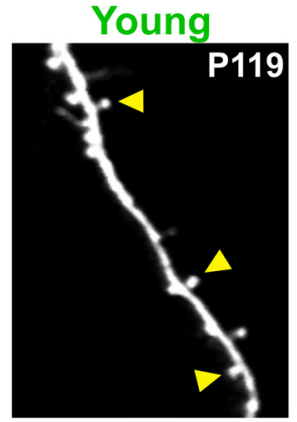

ए
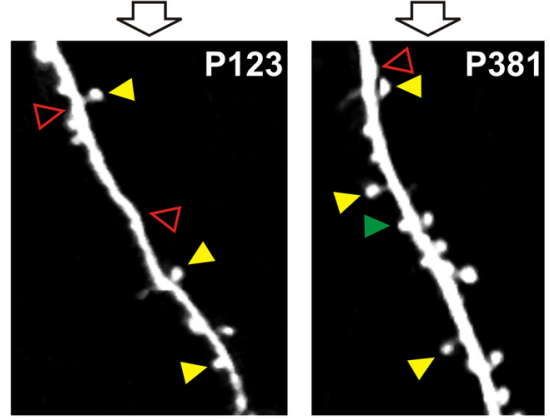

C
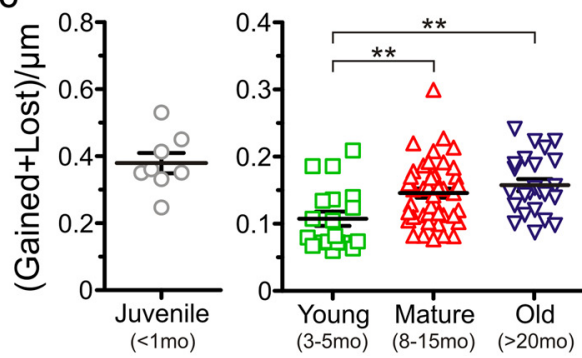

e

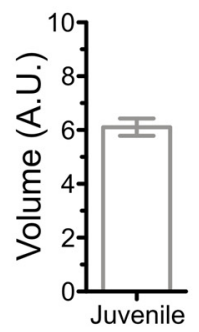

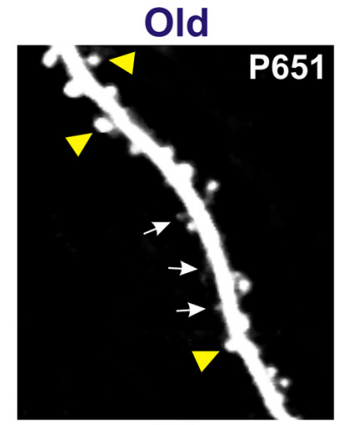
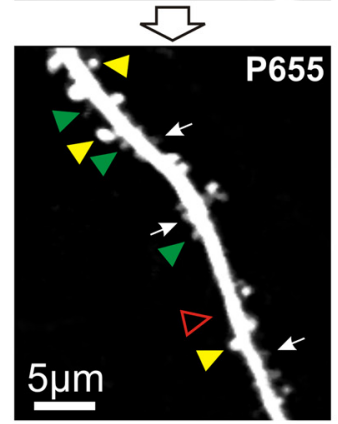

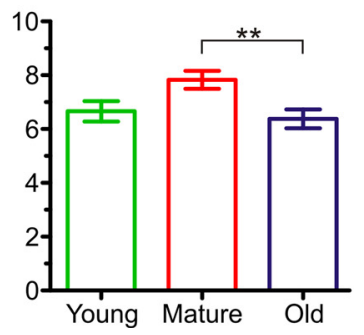

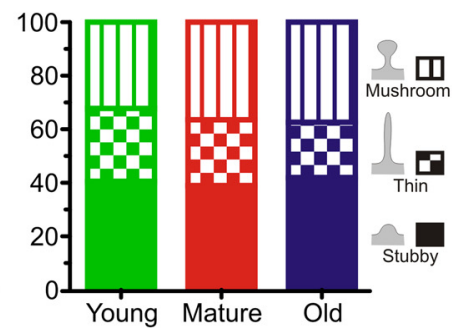

Figure 1. Dendritic spines are more numerous, smaller, and have higher turnover in old mice than in young adult mice. $\boldsymbol{a}$, Representative high-resolution images of apical dendritic segments from L5 pyramidal neurons (top row) acquired with in vivo two-photon microscopy $4 \mathrm{~d}$ apart (bottom row) in juvenile ( $<1$ month; $n=3$ mice), young ( $3-5$ months; $n=7)$, mature ( $8-15$ months; $n=$ 11 ), and old ( $>20$ months; $n=8$ ) mice. All are best projections ( $3-8$ slices, $1.5 \mu \mathrm{m}$ apart). A few examples of persistent spines (yellow arrowheads), gained spines (green arrowheads), and lost spines (open red arrowheads) are shown. Postnatal day is shown in the top right corner. White arrows indicate examples of small dendritic spines that are most frequently found in old mice. $\boldsymbol{b}$, Density of dendritic spines from L5 pyramidal neurons in juvenile $(n=8$ cells), young $(n=19)$, mature $(n=48)$, and old $(n=24)$ mice. Given that the focus of the present investigation was the effect of aging on synapse dynamics during aging in adult mice, the juvenile group was not included in the analysis (ANOVA test) but shown separately as a reference. ${ }^{* * *} p<0.001$, Bonferroni's post hoc test. Each symbol indicates a different pyramidal cell. c, Turnover of spines (\#gained + \#lost spines per $\mu \mathrm{m}$ ) over a period of $4 \mathrm{~d}$ at different ages. ${ }^{* *} p<0.01$, Bonferroni's post hoc test. Each symbol indicates a different pyramidal cell. $\boldsymbol{d}$, Distribution of the different subtypes of dendritic spines (mushroom, thin and stubby) at different ages. $\boldsymbol{e}$, Volume of dendritic spines in juvenile ( $n=304$ spines), young $(n=231)$, mature $(n=410)$, and old $(n=267)$ mice. ${ }^{* *} p<0.01$, Bonferroni's post hoc test. Only the average of the distribution is shown.

ends at the mature stage and, therefore, that age-related impairment in cortical function in somatosensory cortex cannot be attributed to changes in spine density.

The probability of stabilizing new spines is greater in old mice

Recent live imaging studies have demonstrated that cortical circuit function (e.g., learning, tactile perception) and synaptic plasticity is mediated principally by changes in the production, elimination, and/or lifetime of spines. To look for differences in spine dynamics between mature and old mice, we first compared the number of gained and lost spines per micrometer over $4 \mathrm{~d}$ among the adult groups of animals. We found that mature and old mice both gain and lose more spines than young mice (gained: $0.05 \pm 0.01$ spines $/ \mu \mathrm{m}$ for young group vs $0.07 \pm 0.01$ and $0.08 \pm 0.01$ spines $/ \mu \mathrm{m}$ for mature and old groups, ${ }^{*} p<0.05$ and ${ }^{* *} p<0.01$, respectively, Bonferroni's post hoc test; lost: $0.06 \pm 0.01 \mathrm{spines} / \mu \mathrm{m}$ for young group versus $0.08 \pm 0.01$ and $0.08 \pm 0.01$ spines $/ \mu \mathrm{m}$ for mature and old groups, ${ }^{\star} p<0.05$ for both), but there were no significant differences between mature 

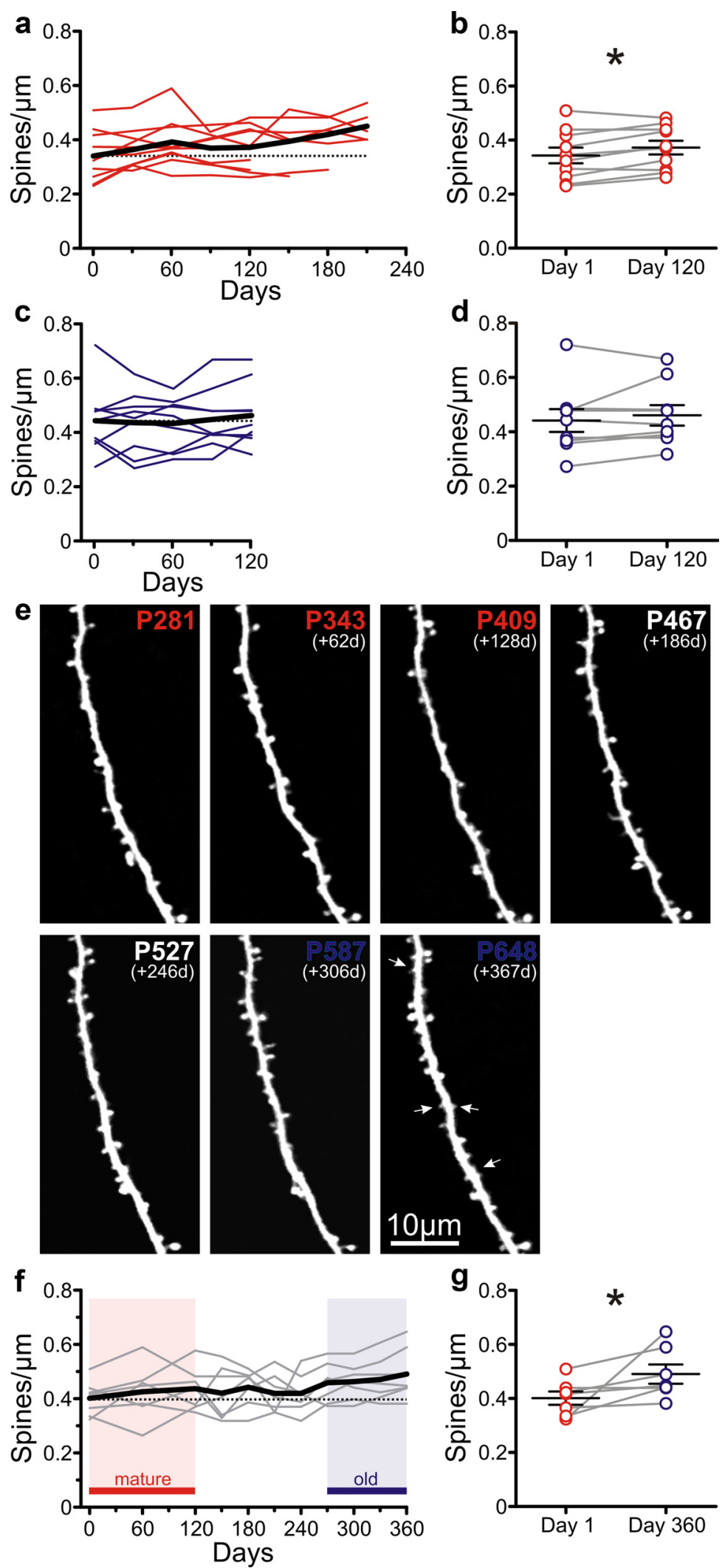

Figure 2. Chronic imaging over 4-12 months shows an increase in spine density between mature and old mice. $\boldsymbol{a}$, Density of dendritic spines as a function of time (4-7 months) in mature mice. Colored lines represent individual pyramidal cells ( $n=10$ from 4 mice); the black line indicates the average. The horizontal dotted line indicates the average spine density at the first imaging session. $\boldsymbol{b}$, Spine density in mature mice at the first imaging session and 120 d later. ${ }^{*} p<0.05$, paired $t$ test; $n=10$ cells. $\boldsymbol{c}$, Spine density as a function of time ( 4 months) in old mice. Lines are as in $\boldsymbol{a}(n=9$ cells from 4 mice). $\boldsymbol{d}$, Spine density in old mice at the first imaging session and 120 d later. $p=0.315$, paired $t$ test; $n=9$ cells. $e$, Time-lapse in vivo two-photon images of an apical dendritic segment taken over 12 months (encompassing the mature and old age groups). All are best projections (4-10 slices, and old mice (Fig. 3a). We then investigated whether the lifetime of spines in these two age groups was different. The half-life of unstable spines was significantly higher in the old group than in the mature group $(21.9 \pm 2.3$ vs $6.2 \pm 0.5 \mathrm{~d}$; $p<0.0001$, extra sum-of-squares $F$ test; Fig. $3 b$ ). In addition to the longer half-life of transient spines, the old group showed a lower fraction of stable (also known as persistent $)$ spines $(0.53 \pm 0.10$ in old group vs $0.40 \pm 0.20$ in mature group; $p<$ 0.0001 , extra sum-of-squares $F$ test; the fraction of stable spines is defined as the plateau of the single exponential decay fit; Fig. $3 b$ ). These results are consistent with previous in vivo imaging studies that show the existence of two types of spines in neocortex: transient spines with very short lifetimes (days) and persistent spines with very long lifetimes (months) (Holtmaat et al., 2005; Zuo et al., 2005). Strikingly, spines in old mice seem to coalesce into a more homogeneous group with intermediate lifetimes (weeks)

Next, we analyzed the probability that new spines are stabilized (Fig. 3c). We scored new spines over a $4 \mathrm{~d}$ period and quantified how many of them were present $30 \mathrm{~d}$ after the first imaging session. Although there were no differences in the density of new spines $(0.078 \pm 0.014$ vs $0.084 \pm 0.010$ new spines $/ \mu \mathrm{m}$ for mature and old groups, respectively; $p=0.759$, unpaired $t$ test; Fig. $3 c, d$ ), the group of old mice showed a more than fourfold higher probability that new dendritic spines were stabilized after a $30 \mathrm{~d}$ period $(0.12 \pm 0.04$ vs $0.55 \pm 0.04$ for mature and old groups, respectively; $p<0.001$, unpaired $t$ test; Fig. $3 c, e$ ). This fits with the notion that spines in old mice tend to have intermediate lifetimes of several weeks.

\section{Higher density and volume of EPBs in old mice}

Little is known about age-related changes in axonal boutons in somatosensory cortex in mice, although increased bouton size has been described in the neostriatum of aged rats (Itzev et al., 2001). In light of the dramatic and unexpected alterations observed in postsynaptic spines, we next investigated the density, turnover, size,

$$
\leftarrow
$$

$1.5 \mu \mathrm{m}$ apart). White arrows indicate examples of very small dendritic spines found most frequently in old mice. $\boldsymbol{f}$, Spine density for $L 5$ pyramidal cells imaged over 12 months $(n=7$ cells). Lines are as in $\boldsymbol{a}$. Red shading indicates the mature stage; blue shading indicates the old stage. $\boldsymbol{g}$, Average spine density in cells imaged over 1 year, at day 1 (mature), and at day 360 (old). ${ }^{*} p<0.05$, paired $t$ test, $n=7$ cells. 

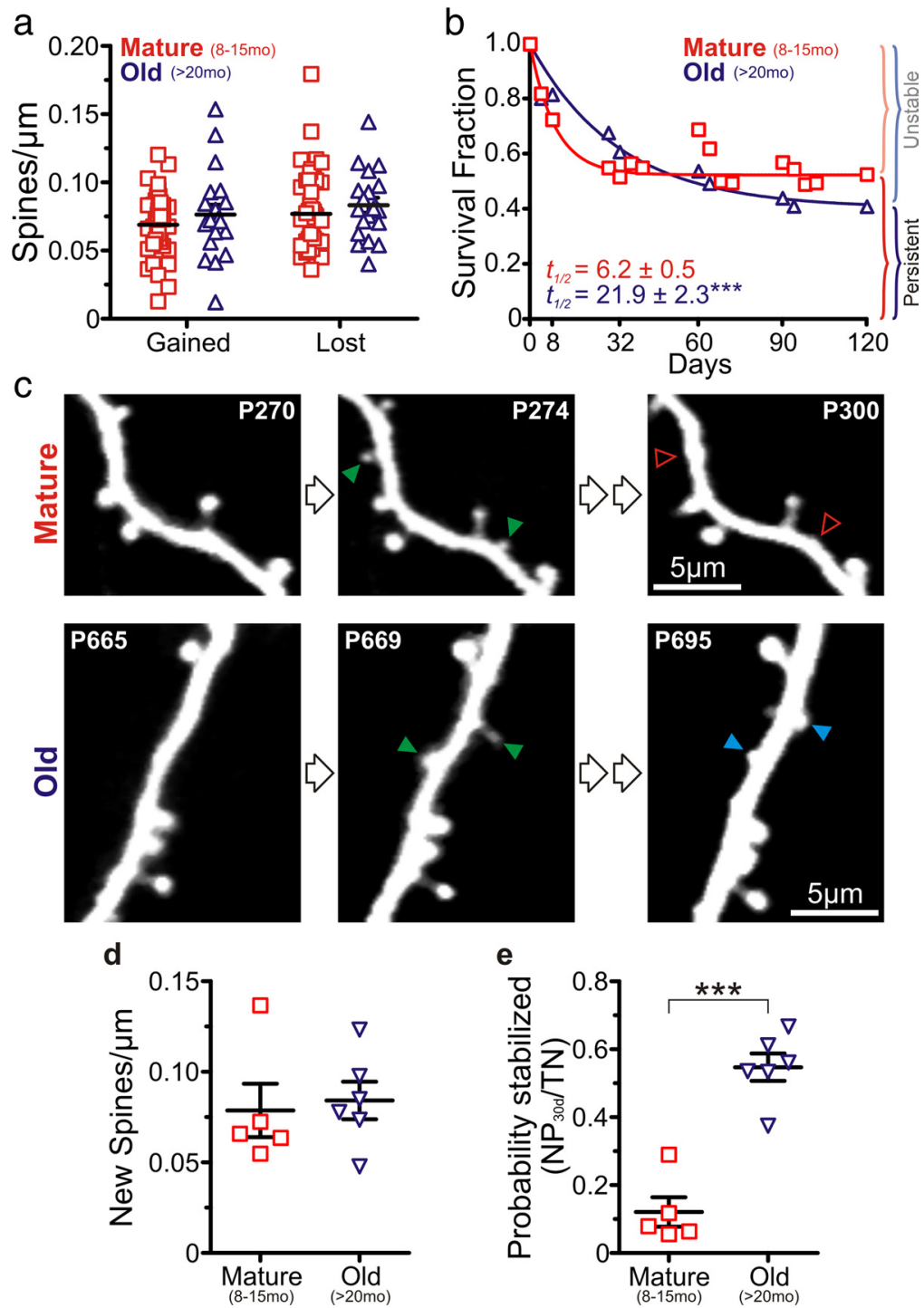

Figure 3. Higher probability of $30 \mathrm{~d}$ spine stabilization but shorter long-term lifetime in old mice compared with mature mice. $\boldsymbol{a}$, Gained and lost spines per unit length of dendrite in mature $(n=46$ cells) and old $(n=24)$ mice (each symbol indicates a different cell). $\boldsymbol{b}$, Average survival fraction of spines for mature ( $n=36$ cells) and old ( $n=21)$ mice over a $120 \mathrm{~d}$ period. Half-life $\left(t_{1 / 2}\right)$ values for both groups were significantly different; ${ }^{* *} p<0.001$, extra sum-of-squares $F$ test. $c$, Representative in vivo two-photon images of apical dendritic segments from $L 5$ pyramidal neurons depicting differences in dendritic spine stabilization between mature (top) and old (bottom) mice. All are best projections (3-5 slices, $1.5 \mu \mathrm{m}$ apart). Green arrowheads indicate gained spines after a $4 \mathrm{~d}$ interval. In the mature group, most of the newly gained spines were lost 4 weeks later (open red arrowheads); however, in the old group, many of the newly gained spines were still present by that time (blue arrowheads). $\boldsymbol{d}$, Density of new dendritic spines after a 4 d imaging interval. $p=0.759$. Each symbol represents a different animal $(n=5$ and 6 mice for mature and old groups, respectively, in $\boldsymbol{d}$ and $\boldsymbol{e}$ ). $\boldsymbol{e}$, Probability of stabilization of new spines over $30 \mathrm{~d}$ in mature and old animals. ${ }^{* *} p<0.001$, unpaired $t$ test.

and probability of stabilization of presynaptic boutons in vivo. The axo-spinous EPBs in type A3 axons from L2/3 and L5 pyramidal neurons are known to be more stable than the apical dendritic spines of L5 neurons with which they sometimes make synapses (Trachtenberg et al., 2002; Holtmaat et al., 2005; De Paola et al., 2006). We performed in vivo two-photon imaging of A3 axons (and their boutons) from presumed L5 and L2/3 cells in somatosensory cortex of mice (Fig. $4 a, b$ ). Visual inspection of image stacks showed an apparent increase in the density of boutons throughout the lifespan of mice (Fig. 4a) and also that bouton size was smallest in the young adult stage and increased again in old mice (Fig. 4a,b).
Quantitative analysis revealed that the density of EPBs was indeed lowest in juvenile mice $(0.08 \pm 0.01 \mathrm{EPBs} / \mu \mathrm{m})$ and nearly doubled throughout life (0.11 \pm 0.01 vs $0.15 \pm 0.01 \mathrm{EPBs} / \mu \mathrm{m}$ in young and old mice, respectively; $p<0.05$, unpaired $t$ test; Fig. $4 c$; however, an ANOVA test did not quite reach statistical significance, $p=0.091)$. Age-dependent changes in EPB turnover resembled the pattern described for dendritic spines, in that it was lowest in the young adult stage and increased thereafter, but again the difference was not significant $(p=0.303$, ANOVA; Fig. 4d). We also quantified bouton volume (see Materials and Methods) and found a progressive increase in the size of EPBs throughout adult life $(p<0.05$ and $p<0.01$ for the mature and old groups, respectively, when compared with the young group; Bonferroni's post hoc test; Fig. $4 b, e)$. This was caused mostly by the presence of fewer small EPBs and more large EPBs, rather than a similar increase in size affecting all EPBs (data not shown).

Just as for spines, we also analyzed the stabilization of new EPBs by calculating the fraction of new boutons that appeared in a $4 \mathrm{~d}$ interval and was still present $30 \mathrm{~d}$ later. The density of newly formed boutons was very low and similar in magnitude in both mature and old mice $(0.026 \pm 0.007$ vs $0.022 \pm 0.003 \mathrm{EPBs} / \mu \mathrm{m}$ for mature and old groups, respectively; $p=0.621$, unpaired $t$ test; Fig. $4 f, g)$. However, the stabilization of new EPBs was nearly fourfold higher in the old group of mice $(0.14 \pm 0.06$ vs $0.52 \pm$ 0.04 for mature and old groups, respectively; $p<0.001$, unpaired $t$ test; Fig. $4 f, h)$. Thus, although axon boutons get larger while spines shrink in old mice, presynaptic and postsynaptic elements exhibit similar age-related changes in dynamics.

\section{Dendritic spines and axon boutons of old mice establish normal-}

appearing synapses

In adult mice, unstable (also known as transient) spines with lifetimes $<4 \mathrm{~d}$ are less likely to establish synapses than persistent spines (Knott et al., 2006). Considering that unstable spines usually have much smaller volumes than persistent spines, we wondered whether the more abundant small spines in very old mice fail to establish synapses, which could further contribute to the age-related decline in brain function. We performed serial block face-scanning electron microscopy using the focused ion beam scanning electron microscope, imaging volumes containing axons, and dendrites seen in vivo with two-photon microscopy in old mice. After $3 \mathrm{D}$ reconstructions to identify each imaged neurite, we found that all of the reconstructed spines ( six of six), including the smallest ones, established asymmetric synapses with neighboring boutons (Fig. $5 a-c)$. As for type A3 axons, serial-section electron microscopy 
a
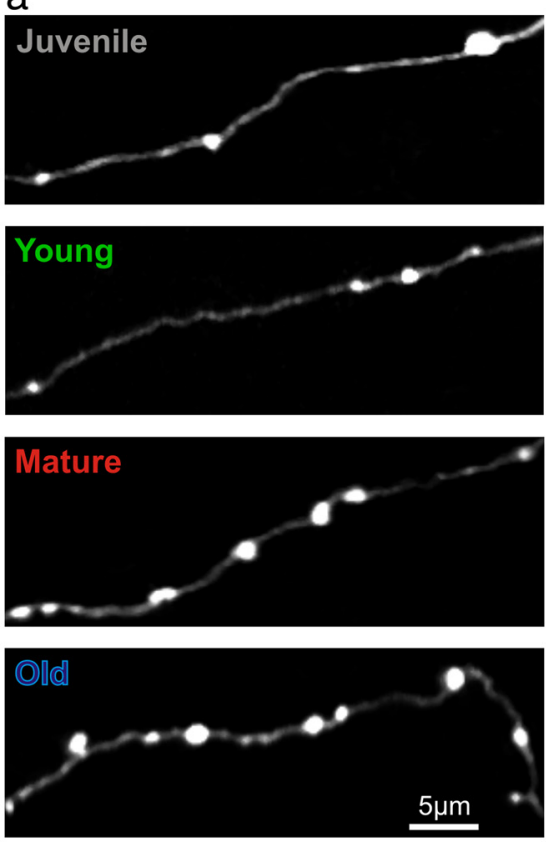

f

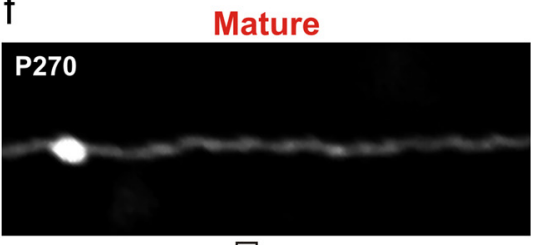

5
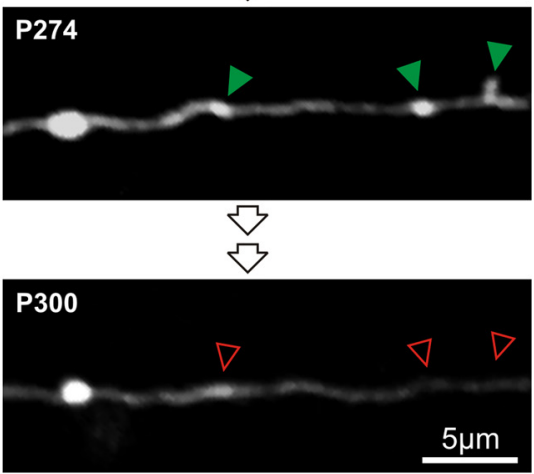

b
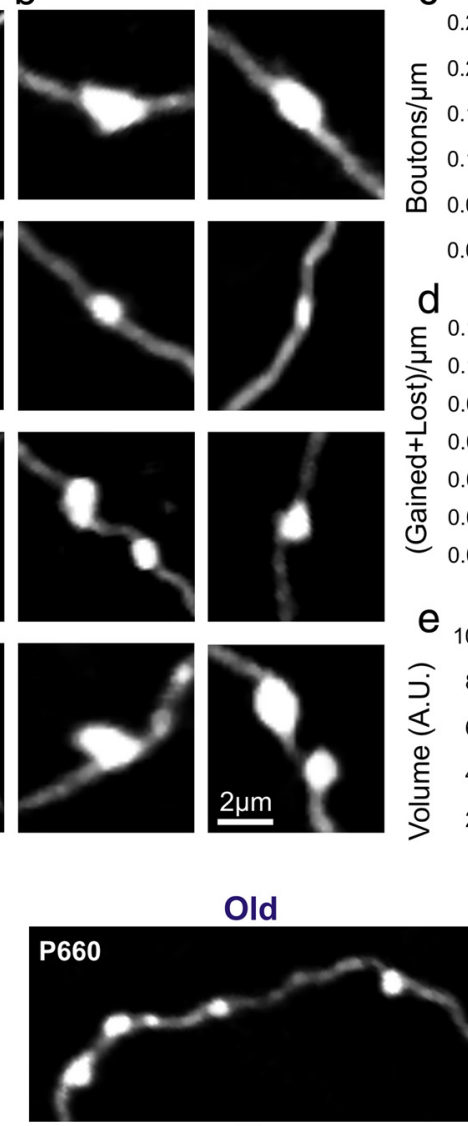

5
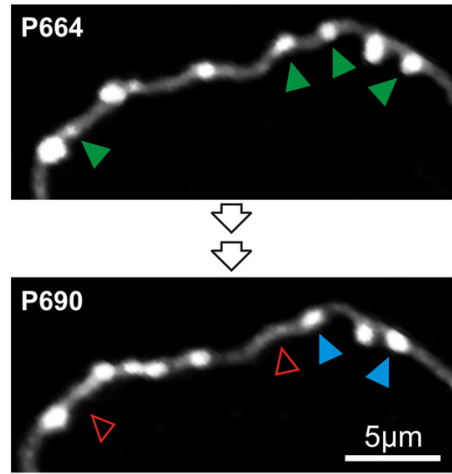

\section{C}
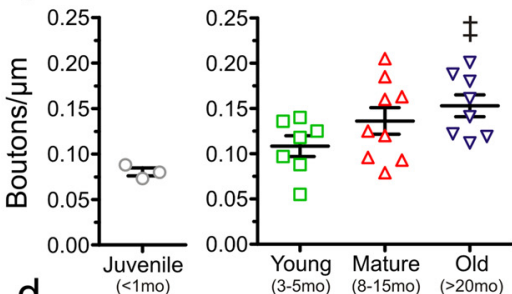

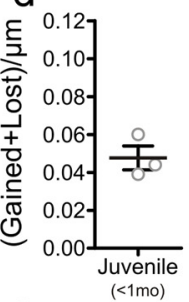
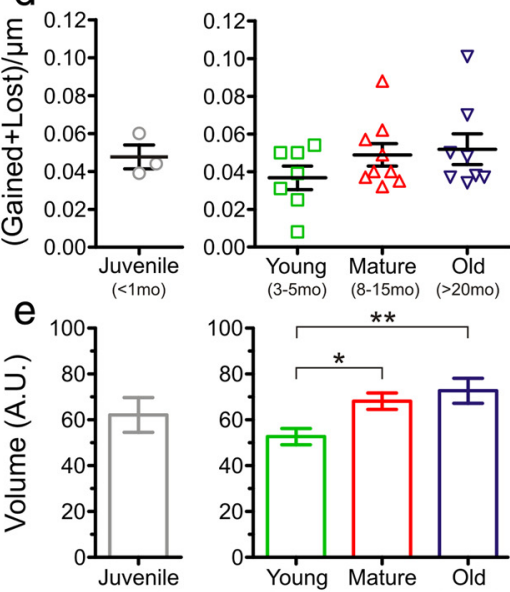
(<1mo)

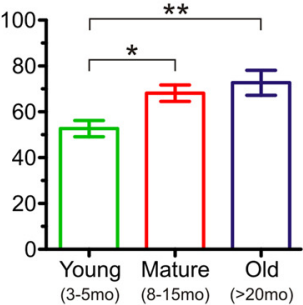

g

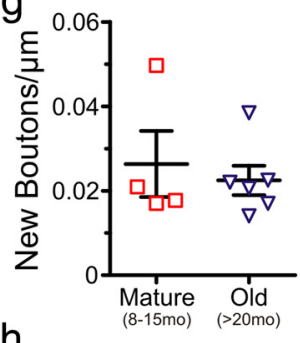

h

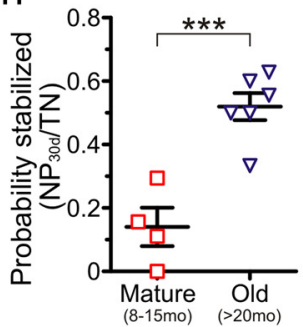

Figure 4. Higher density and volume of en passant axonal boutons in old mice compared with young adult mice. $\boldsymbol{a}$, Examples of in vivo two-photon images of EPBs on type A3 axons (presumably from $L 5$ cortical pyramidal neurons) in juvenile, young, mature, and old mice. $\boldsymbol{b}$, Additional examples of the relative size of representative EPBs at higher magnification at different ages. $\boldsymbol{c}$, Density of EPBs at different ages. As in Figure 1, the juvenile group is shown separately as a reference. ${ }^{\ddagger} p<0.05$ young versus old mice, unpaired $t$ test. Individual symbols represent different mice $(n=$ $3,7,9$, and 8 mice for the juvenile, young, mature, and old groups, respectively, in $\mathbf{c}$ and $\boldsymbol{d}$ ). $\boldsymbol{d}$, Turnover of EPBs (\#gained + \#lost spines per $\mu \mathrm{m}$ ) over a period of $4 \mathrm{~d}$ at different ages. Individual symbols represent different mice. $e$, Volume of $\operatorname{EPBs}\left(n=219,405\right.$, and 267 boutons for the young, mature, and old groups, respectively) at different ages. ${ }^{*} p<0.05$; ${ }^{* *} p<0.01$, Bonferroni's post hoc test. $\boldsymbol{f}$, Representative in vivo two-photon images of A3 axonal segments depicting differences in EPB stabilization between mature (left) and old (right) mice. All are best projections (4-7 slices, $1.5 \mu \mathrm{m}$ apart). Green arrowheads indicate gained EPBs after a $4 \mathrm{~d}$ interval. In the mature group, most of the newly gained EPBs were lost 4 weeks later (open red arrowheads); however, in the old group, many of the EPBs were still present by that time (blue arrowheads). $\boldsymbol{g}$, Density of new EPBs after a 4 dimaging interval. $p=0.621 ; n=4$ and 6 mice for the mature and old groups, respectively, in $\boldsymbol{g}$ and $\boldsymbol{h}$. Each symbol represents a different animal. $\boldsymbol{h}$, Probability of stabilization of new EPBs over $30 \mathrm{~d}$ in mature and old animals. ${ }^{* * *} p<0.001$, unpaired $t$ test. Each symbol represents a different animal.

(SSEM) reconstructions showed that even the very large EPBs (four of four) found in old mice also established normal-looking synapses (Fig. $5 d, e$ ). We also investigated whether the higher density of spines and the larger size of boutons in old mice might result in the formation of multiple-synapse boutons (MSBs), the prevalence of which is increased after LTP (Toni et al., 1999) and associative learning (Geinisman et al., 2001). We found that neither the spines nor the EPBs that we reconstructed established
MSBs. However, it is possible that we may have missed MSBs considering the relatively low number of reconstructed axons (Holderith et al., 2012).

\section{Discussion}

Age-related cognitive impairment has been reported across different mammalian species (Magnusson et al., 2003; von Bohlen und Halbach et al., 2006; Morrison and Baxter, 2012). Older 


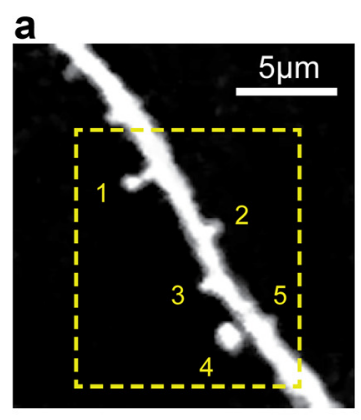

C spine 3

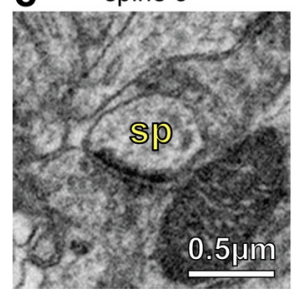

b

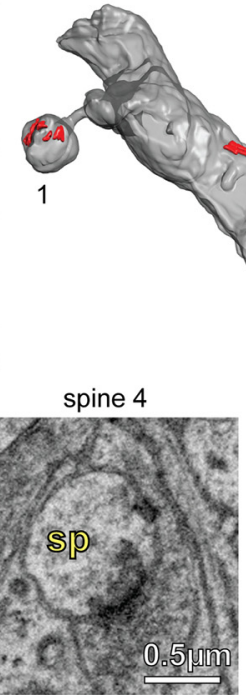

d

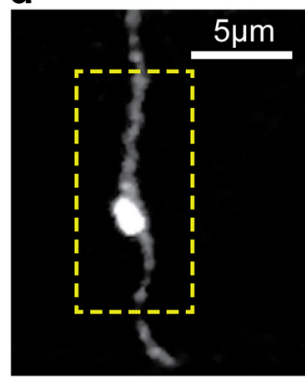

f

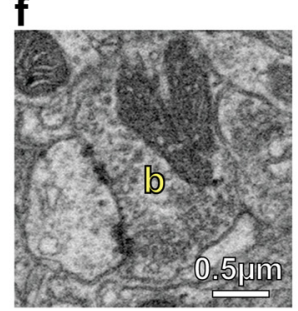

e

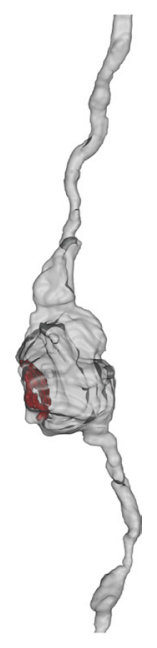

Figure 5. The small spines and large EPBs of old mice make synapses. $\boldsymbol{a}$, In vivo two-photon image of an apical dendritic segment from a $L 5$ neuron that was subsequently reconstructed with SSEM. Note how two of the spines had small volumes. $\boldsymbol{b}$, SSEM reconstruction of a portion of the dendrite shown in $\boldsymbol{a}$ with four spines. The areas shaded in red indicate synapses. Note that every spine, even those with very small volumes, makes asymmetric synapses. c, EM photomicrographs of spines (sp) 3 and 4 from a.d, In vivo two-photon image of an A3 axon with an EPB that was subsequently reconstructed with SSEM. $\boldsymbol{e}$, SSEM reconstruction of a portion of the axon shown in $\boldsymbol{a}$. The areas shaded in red represent synapses. $\boldsymbol{f}$, EM photomicrograph of the EPB (b) from $\boldsymbol{d}$.

individuals also exhibit defects in motor function (Mattay et al., 2002) and in sensory tactile discrimination (Dinse et al., 2006; Kalisch et al., 2009). What is the neuroanatomical basis for this age-related global impairment in cortical function? Because excitatory synapses represent the overwhelming majority of connections in the cortex, the density of dendritic spines has traditionally been the focus of investigations of circuit integrity in response to changes in sensory experience, learning, or disease. But previous studies using postmortem tissue that examined the fate of dendritic spines with normal aging led to conflicting results and could only examine static parameters (density or morphology). The goal of this study was to investigate age-related changes in synaptic dynamics in somatosensory cortex using in vivo two-photon microscopy through cranial windows in GFP-M mice throughout their entire lifespan.

\section{Synaptic dynamics are profoundly altered in old mice, but there is no loss of synapses}

A priori, one intuitively imagines that functional neurological deficits of normal aging would be associated with decreases in synaptic connectivity, and indeed the majority of prior Golgi studies reported spine loss (Feldman and Dowd, 1975; Leuba, 1983; Wallace et al., 2007). In addition, because aging leads to problems with working memory [i.e., memory storage over short time scales (Park and Reuter-Lorenz, 2009)], we anticipated that old mice would have lower numbers of thin spines, since they tend to have the shortest lifetimes. Given that axon boutons are less dynamic than spines in normal adult mice (De Paola et al., 2006), we predicted that their density, size, and dynamics would not change in old mice. We focused much of our analysis in the last stages of adult life and identified important differences between mature mice ( $8-15$ months) and old mice ( $>20$ months). We find the following: (1) spine and bouton density increases gradually throughout adult life and remains stable in old mice; (2) spines are smaller in old adult mice than in mature mice, and bouton size increases throughout adulthood but is stable between mature and old stages; (3) the probability of stabilization of new spines and boutons over $30 \mathrm{~d}$ increases drastically between ma- ture and old mice; and (4) long-term stability (months) of spines is reduced in old mice compared with mature mice.

What about other cell types and other brain areas? We only imaged dendrites of L5 neurons and type A3 axons in primary somatosensory cortex, so we cannot rule out that dendritic spines or axon boutons from other cell types, or from other brain areas, might behave differently with aging. Because the decline in working memory has been attributed in part to defects in inhibitory networks [e.g., selection of irrelevant information into the contents of working memory (Park and Reuter-Lorenz, 2009)], it will be interesting to examine interneuron dendrites, which are more dynamic in normal adult mice that pyramidal dendrites (Lee et al., 2006). We focused our imaging on the barrel cortex because our previous investigations into spine development and plasticity were done there too (Cruz-Martín et al., 2010; Mostany et al., 2010). But it is possible that synapses in different cortical areas might experience different fates with normal aging. For example, the primary somatosensory cortex is not the only brain region involved in tactile discrimination, and similar or different synaptic alterations in secondary somatosensory areas, thalamus or entirely different brain regions, could underlie the age-dependent deficits in sensory perception. Future in vivo imaging studies will also need to address whether age-related cognitive impairment is also associated with similar alterations in synaptic stability or whether it is caused by synaptic loss instead. Indeed, previous studies indicate that the dorsolateral prefrontal cortex, which is important for working memory (Fuster, 2008), may be more susceptible to agedependent spine loss (Jacobs et al., 1997; Wallace et al., 2007; Dumitriu et al., 2010).

Our novel results are important for several reasons. First, they highlight the fact that there is no loss of synapses in old animals. Second, the fact that spines shrink in old animals likely results in weaker synapses. Our SSEM reconstructions of previously imaged dendrites (and large axon boutons) confirmed that, regardless of the size, spines in old mice established normal-appearing synapses, so again we have no reason to believe that synapses are lost with normal aging. Of note, because only a small fraction of the type A3 EPBs are likely to be presynaptic to the dendritic 


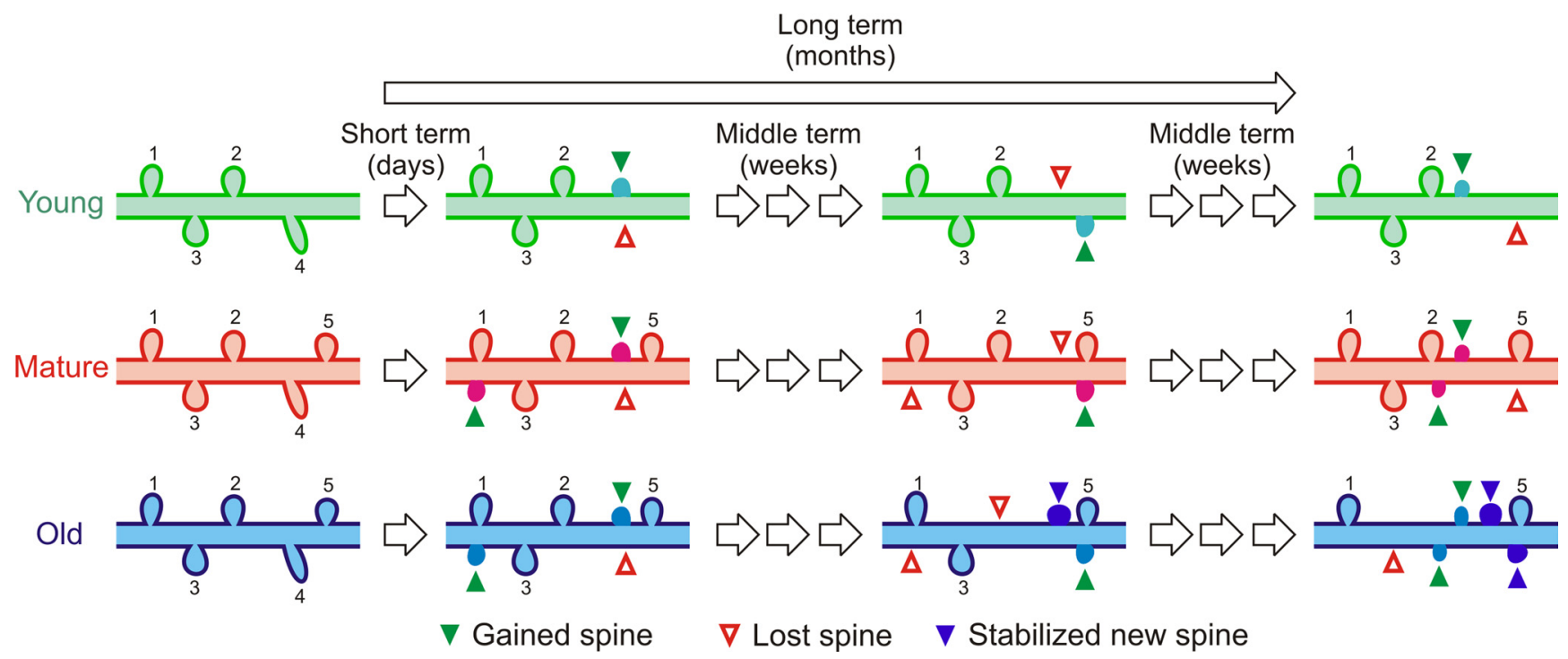

Figure 6. Proposed model for changes in dendritic spine dynamics during normal aging. Based on our own and previously published data, we introduced a number of variables and conditions to the model, including density $(d)\left[d_{\text {young }}<d_{\text {mature }} \approx d_{\text {old }}\right.$, short-term (e.g., $4 \mathrm{~d}$ ) turnover (TORst) [TORst young $_{\text {o }}<$ TORst $_{\text {mature }} \approx$ TORst old $_{1}$, half-life of unstable dendritic spines $\left(t_{1 / 2}\right)\left[t_{1 / 2 y o u n g} \approx\right.$ $t_{1 / 2 \text { mature }} \ll t_{1 / 2 \text { old }}$, and probability of stabilization of new spines over $30 \mathrm{~d}$ (PSns) [PSns mature $\ll$ PSns old $_{\text {d }}$. Because L5 neurons in old mice stabilize a higher percentage of new spines than mature mice (over $30 \mathrm{~d}$ ) without changing dendritic spine density, the overall lifetime of spines over longer periods of time is lower in the old mice, and very few of the original spines ( 1 and 5 ) are still present after several months. On the other hand, young and mature mice have a very distinct population of unstable spines, with short lifetimes and a higher percentage of spines that are persistent over the long term. Green arrowheads indicate gained spines, empty red arrowheads indicate the loss of a dendritic spine, and blue arrowheads indicate stabilized new spines. New and stabilized new spines were colored differently for better visualization. The proportional volume of spines at different ages also reflects our results.

spines that we imaged, the growth of boutons and shrinkage of spines that we see in old mice are not mutually exclusive phenomena. Third, the most remarkable change that occurs at the last stage of life is a profound change in synaptic dynamics that could affect learning and plasticity.

\section{A proposed model of spine dynamics throughout life}

Previous in vivo imaging studies have demonstrated the existence of two populations of dendritic spines in the somatosensory cortex of young adult mice: approximately one-fourth of spines are unstable $(\tau \sim 4.5 \mathrm{~d})$ and the majority of spines are stable $(s=$ $73 \%$ ), meaning they persist for many months (Holtmaat et al., 2005). In our mature (m) animals, we also find two populations of spines, but perhaps because of their somewhat older age [compared with adult mice used in the study by Holtmaat et al. (2005); 6 months[ we find that unstable spines have a longer half-life $\left(\tau_{\mathrm{m}}=8.9 \mathrm{~d}\right)$ and that persistent spines make up a slightly lower fraction $\left(s_{\mathrm{m}}=53 \%\right)$. In contrast, in the old (o) group, we find that the half-life of transient spines is much longer $\left(\tau_{\mathrm{o}}=31.6 \mathrm{~d}\right)$ and only a minority of spines is stable over periods of several months $\left(s_{\mathrm{o}}\right.$ $=41 \%$ ). This explains why the probability of spine stabilization over $30 \mathrm{~d}$ is higher in old mice, as $\sim 55 \%$ of newly added spines are still present 1 month later compared with only $\sim 12 \%$ in the mature group. Thus, over the long term (several months), most of the dendritic spines in the older group are replaced, whereas in the mature and young groups, most of the spines are stable spines (Fig. 6).

In simpler terms, we find a relative loss of the highly unstable transient synapses that have been associated with learning, as well as a loss of the superstable persistent synapses that are linked to long-term memory storage (Kasai et al., 2010). The more homogeneous population of spines with intermediate lifetimes seen in old mice would reduce perceptive flexibility and could explain challenges that older individuals experience in both learning new tasks and storing memories. It would also explain why older adults are less likely to compensate for brain injury (e.g., stroke) through neural plasticity. But could any of the synaptic changes we describe in old animals also bear an advantage for the aging neocortex?

\section{Compensatory versus maladaptive plasticity of aging cortical synapses?}

The selective pruning and stabilization of dendritic spines that we and others have observed between juvenile and young adult mice (Holtmaat et al., 2005; Zuo et al., 2005; Fig. 1b) is thought to reflect a phase of experience-dependent refinement of neural connectivity during development that makes circuits less redundant and therefore more efficient (Lichtman and Colman, 2000). When compared with spines in young mice, those in old mice had a significantly higher density, higher $4 \mathrm{~d}$ turnover rates, and a smaller size. In essence, spines of old mice resemble more closely those of juvenile mice than of young adult animals.

The young adult stage (3-5 months) seems to represent a time when the neocortex has reached its maximum efficiency: it uses the lowest number of dendritic spines with the lowest turnover, thus economizing energetic resources. Optimal learning and memory storage are presumably accomplished through conservative use of steady-state synaptic turnover and minimal redundant wiring. In this sense, the apparent "rejuvenilization" of spines in old mice would seem like a major disadvantage. The high density of spines and lower rates of long-term spine retention in the somatosensory cortex in old mice would create superfluous circuits that waste resources, whereas their smaller size would result in weaker synapses. It is not difficult to imagine how these alterations could explain the impairments in tactile discrimination (or cognition, should similar changes occur in relevant brain areas) of older individuals, as well as the lower potential for neural repair of the aged brain (Achard and Bullmore, 2007; Jost et al., 2011; Yeoman et al., 2012).

On the other hand, some of the changes in EPBs and spines that we observed could be compensatory. The higher rates of 
spine and bouton stabilization over $30 \mathrm{~d}$ might represent a compromise that ensures efficient learning and memory over intermediate time scales. For instance, whisker trimming also leads to a higher stabilization of new spines (Holtmaat et al., 2006; Wilbrecht et al., 2010), which implies that L5 neurons in old mice are behaving as if they were encountering new sensory experiences. Similarly, the increase in bouton size in old animals might be a compensatory change for the decreasing size of spines. Thus, at least some of the changes we observed in the mouse somatosensory cortex could represent the types of adaptive mechanisms that a resourceful aging brain might create to make up for its deficient synaptic transmission (Park and Reuter-Lorenz, 2009; Grady, 2012).

Future investigations, including combined behavioral and imaging studies, will be critical to definitively establish a causal relationship between spine and bouton changes (i.e., turnover, size, and lifetime) and aged-related deficits. This will allow us to distinguish between synaptic changes that directly cause deficits in tactile discrimination (or other decreases in brain function, including cognitive impairment) and those that are compensatory or entirely unrelated. Ultimately, the answer to this and other open questions about normal brain aging will allow us to use our growing knowledge of signaling pathways or behavioral interventions that can regulate synaptic number, dynamics, and strength for therapeutic purposes.

\section{References}

Achard S, Bullmore E (2007) Efficiency and cost of economical brain functional networks. PLoS Comp Biol 3:e17. CrossRef

Adams I, Jones DG (1982) Quantitative ultrastructural changes in rat cortical synapses during early-, mid- and late-adulthood. Brain Res 239:349363. CrossRef Medline

Anderson B, Rutledge V (1996) Age and hemisphere effects on dendritic structure. Brain 119:1983-1990. CrossRef Medline

Benice TS, Rizk A, Kohama S, Pfankuch T, Raber J (2006) Sex-differences in age-related cognitive decline in $\mathrm{C} 57 \mathrm{BL} / 6 \mathrm{~J}$ mice associated with increased brain microtubule-associated protein 2 and synaptophysin immunoreactivity. Neuroscience 137:413-423. CrossRef Medline

Bishop D, Nikić I, Brinkoetter M, Knecht S, Potz S, Kerschensteiner M, Misgeld T (2011) Near-infrared branding efficiently correlates light and electron microscopy. Nat Methods 8:568-570. CrossRef Medline

Bloss EB, Janssen WG, Ohm DT, Yuk FJ, Wadsworth S, Saardi KM, McEwen BS, Morrison JH (2011) Evidence for reduced experience-dependent dendritic spine plasticity in the aging prefrontal cortex. J Neurosci 31 : 7831-7839. CrossRef Medline

Connor JR Jr, Diamond MC, Johnson RE (1980) Aging and environmental influences on two types of dendritic spines in the rat occipital cortex. Exp Neurol 70:371-379. CrossRef Medline

Cruz-Martín A, Crespo M, Portera-Cailliau C (2010) Delayed stabilization of dendritic spines in fragile X mice. J Neurosci 30:7793-7803. CrossRef Medline

De Paola V, Holtmaat A, Knott G, Song S, Wilbrecht L, Caroni P, Svoboda K (2006) Cell type-specific structural plasticity of axonal branches and boutons in the adult neocortex. Neuron 49:861-875. CrossRef Medline

Dinse HR, Kleibel N, Kalisch T, Ragert P, Wilimzig C, Tegenthoff M (2006) Tactile coactivation resets age-related decline of human tactile discrimination. Ann Neurol 60:88-94. CrossRef Medline

Dumitriu D, Hao J, Hara Y, Kaufmann J, Janssen WG, Lou W, Rapp PR, Morrison JH (2010) Selective changes in thin spine density and morphology in monkey prefrontal cortex correlate with aging-related cognitive impairment. J Neurosci 30:7507-7515. CrossRef Medline

Feldman ML, Dowd C (1975) Loss of dendritic spines in aging cerebral cortex. Anat Embryol 148:279-301. CrossRef Medline

Feng G, Mellor RH, Bernstein M, Keller-Peck C, Nguyen QT, Wallace M, Nerbonne JM, Lichtman JW, Sanes JR (2000) Imaging neuronal subsets in transgenic mice expressing multiple spectral variants of GFP. Neuron 28:41-51. CrossRef Medline

Fiala J, Harris K (2001) Cylindrical diameters method for calibrating section thickness in serial electron microscopy. J Microsc 202:468-472. CrossRef Medline

Freeman SH, Kandel R, Cruz L, Rozkalne A, Newell K, Frosch MP, HedleyWhyte ET, Locascio JJ, Lipsitz LA, Hyman BT (2008) Preservation of neuronal number despite age-related cortical brain atrophy in elderly subjects without Alzheimer disease. J Neuropathol Exp Neurol 67:12051212. CrossRef Medline

Fuster JM (2008) The prefrontal cortex, Ed 4. London: Academic.

Geinisman Y, Berry RW, Disterhoft JF, Power JM, Van der Zee EA (2001) Associative learning elicits the formation of multiple-synapse boutons. J Neurosci 21:5568-5573. Medline

Grady C (2012) The cognitive neuroscience of ageing. Nat Rev Neurosci 13:491-505. CrossRef Medline

Hof P, Morrison J (2004) The aging brain: morphomolecular senescence of cortical circuits. Trends Neuosci 27:607-613. CrossRef Medline

Holderith N, Lorincz A, Katona G, Rózsa B, Kulik A, Watanabe M, Nusser Z (2012) Release probability of hippocampal glutamatergic terminals scales with the size of the active zone. Nat Neurosci 15:988-997. CrossRef Medline

Holtmaat A, Svoboda K (2009) Experience-dependent structural synaptic plasticity in the mammalian brain. Nat Rev Neurosci 10:647-658. CrossRef Medline

Holtmaat AJ, Trachtenberg JT, Wilbrecht L, Shepherd GM, Zhang X, Knott GW, Svoboda K (2005) Transient and persistent dendritic spines in the neocortex in vivo. Neuron 45:279-291. CrossRef Medline

Holtmaat A, Wilbrecht L, Knott GW, Welker E, Svoboda K (2006) Experience-dependent and cell-type-specific spine growth in the neocortex. Nature 441:979-983. CrossRef Medline

Holtmaat A, Bonhoeffer T, Chow DK, Chuckowree J, De Paola V, Hofer SB, Hübener M, Keck T, Knott G, Lee WC, Mostany R, Mrsic-Flogel TD, Nedivi E, Portera-Cailliau C, Svoboda K, Trachtenberg JT, Wilbrecht L (2009) Long-term, high-resolution imaging in the mouse neocortex through a chronic cranial window. Nat Protoc 4:1128-1144. CrossRef Medline

Itzev D, Lolova I, Lolov S, Usunoff KG (2001) Age-related changes in the synapses of the rat's neostriatum. Arch Physiol Biochem 109:80-89. CrossRef Medline

Jacobs B, Driscoll L, Schall M (1997) Life-span dendritic and spine changes in areas 10 and 18 of human cortex: a quantitative Golgi study. J Comp Neurol 386:661-680. CrossRef Medline

Jost K, Bryck RL, Vogel EK, Mayr U (2011) Are old adults just like low working memory young adults? Filtering efficiency and age differences in visual working memory. Cereb Cortex 21:1147-1154. CrossRef Medline

Kalisch T, Ragert P, Schwenkreis P, Dinse HR, Tegenthoff M (2009) Impaired tactile acuity in old age is accompanied by enlarged hand representations in somatosensory cortex. Cereb Cortex 19:1530-1538. CrossRef Medline

Kasai H, Fukuda M, Watanabe S, Hayashi-Takagi A, Noguchi J (2010) Structural dynamics of dendritic spines in memory and cognition. Trends Neurosci 33:121-129. CrossRef Medline

Knott GW, Holtmaat A, Wilbrecht L, Welker E, Svoboda K (2006) Spine growth precedes synapse formation in the adult neocortex in vivo. Nat Neurosci 9:1117-1124. CrossRef Medline

Knott G, Rosset S, Cantoni M (2011) Focused ion beam milling and scanning electron microscopy of brain tissue. J Vis Exp 53:e2588.

Lee WC, Huang H, Feng G, Sanes JR, Brown EN, So PT, Nedivi E (2006) Dynamic remodeling of dendritic arbors in GABAergic interneurons of adult visual cortex. PLoS Biol 4:e29. CrossRef Medline

Leuba G (1983) Aging of dendrites in the cerebral cortex of the mouse. Neuropathol Appl Neurol 9:467-542. CrossRef

Lichtman JW, Colman H (2000) Synapse elimination and indelible memory. Neuron 25:269-278. CrossRef Medline

Magnusson KR, Scruggs B, Aniya J, Wright KC, Ontl T, Xing Y, Bai L (2003) Age-related deficits in mice performing working memory tasks in a water maze. Behav Neurosci 117:485-495. CrossRef Medline

Mattay VS, Fera F, Tessitore A, Hariri AR, Das S, Callicott JH, Weinberger DR (2002) Neurophysiological correlates of age-related changes in human motor function. Neurology 58:630-635. CrossRef Medline

Morrison JH, Baxter M (2012) The ageing cortical synapse: hallmarks and implications for cognitive decline. Nat Rev Neurosci 13:240-250. CrossRef Medline 
Mostany R, Portera-Cailliau C (2008) A craniotomy surgery procedure for chronic brain imaging. J Vis Exp 12:e680.

Mostany R, Chowdhury TG, Johnston DG, Portonovo SA, Carmichael ST, Portera-Cailliau C (2010) Local hemodynamics dictate long-term dendritic plasticity in peri-infarct cortex. J Neurosci 30:14116-14126. CrossRef Medline

Murphy TH, Corbett D (2009) Plasticity during stroke recovery: from synapse to behaviour. Nat Rev Neurosci 10:861-872. CrossRef Medline

Page TL, Einstein M, Duan H, He Y, Flores T, Rolshud D, Erwin JM, Wearne SL, Morrison J, Hof PR (2002) Morphological alterations in neurons forming corticocortical projections in the neocortex of aged Patas monkeys. Neurosci Lett 317:37-41. CrossRef Medline

Park DC, Reuter-Lorenz P (2009) The adaptive brain: aging and neurocognitive scaffolding. Annu Rev Psychol 60:173-196. CrossRef Medline

Peters A, Sethares C, Luebke JI (2008) Synapses are lost during aging in the primate prefrontal cortex. Neuroscience 152:970-981. CrossRef Medline

Pologruto TA, Sabatini BL, Svoboda K (2003) ScanImage: flexible software for operating laser scanning microscopes. Biomed Eng Online 2:13. CrossRef Medline

Russell ES (1966) Lifespan and aging patterns. In: Biology of the laboratory mouse, by the staff of The Jackson Laboratory, Ed 2 (Green EL, ed), pp 511-519. New York: Dover.

Spires-Jones TL, Meyer-Luehmann M, Osetek JD, Jones PB, Stern EA, Bacskai BJ, Hyman BT (2007) Impaired spine stability underlies plaque-related spine loss in an Alzheimer's disease mouse model. Am J Pathol 171:1304-1311. CrossRef Medline
Tigges J, Herndon JG, Peters A (1990) Neuronal population of area 4 during the life span of the rhesus monkey. Neurobiol Aging 11:201-208. CrossRef Medline

Toni N, Buchs PA, Nikonenko I, Bron CR, Muller D (1999) LTP promotes formation of multiple spine synapses between a single axon terminal and a dendrite. Nature 402:421-425. CrossRef Medline

Trachtenberg JT, Chen BE, Knott GW, Feng G, Sanes JR, Welker E, Svoboda $\mathrm{K}$ (2002) Long-term in vivo imaging of experience-dependent synaptic plasticity in adult cortex. Nature 420:788-794. CrossRef Medline

von Bohlen und Halbach O, Zacher C, Gass P, Unsicker K (2006) Agerelated alterations in hippocampal spines and deficiencies in spatial memory in mice. J Neurosci Res 83:525-531. CrossRef Medline

Wallace M, Frankfurt M, Arellanos A, Inagaki T, Luine V (2007) Impaired recognition memory and decreased prefrontal cortex spine density in aged female rats. Ann N Y Acad Sci 1097:54-61. CrossRef Medline

Wilbrecht L, Holtmaat A, Wright N, Fox K, Svoboda K (2010) Structural plasticity underlies experience-dependent functional plasticity of cortical circuits. J Neurosci 30:4927-4932. CrossRef Medline

Yeoman M, Scutt G, Faragher R (2012) Insights into CNS ageing from animal models of senescence. Nat Rev Neurosci 13:435-445. CrossRef Medline

Yu X, Zuo Y (2011) Spine plasticity in the motor cortex. Curr Opin Neurobiol 21:169-174. CrossRef Medline

Zuo Y, Lin A, Chang P, Gan WB (2005) Development of long-term dendritic spine stability in diverse regions of cerebral cortex. Neuron 46:181189. CrossRef Medline 